\title{
CARACTERIZAÇÃO E APROVEITAMENTO DE SUBPRODUTOS DA INDÚSTRIA CERVEJEIRA
}

\author{
Aline F. Rizzanti Pereira*, Julie S. Jisaka, Aline Duarte Correa de Brito, Caroline Joy Steel
}

\section{Resumo}

A reutilização de resíduos agroindustriais é de grande importância, uma vez que esses subprodutos apresentam uma composição nutricional riquíssima. No presente trabalho, foram analisadas as composições dos três principais subprodutos da indústria cervejeira: o resíduo úmido de cervejaria (RUC), o excesso de levedura (LEV) e o pó de malte (PDM), afim de produzir misturas extrudáveis com destinação à alimentação animal. Utilizando um delineamento experimental de misturas, foram extrusados 9 ensaios com diferentes proporções dos resíduos. Os produtos, que foram secos após a extrusão, apresentaram cerca de 17\% de proteínas, e suas propriedades tecnológicas - índice de expansão (IE), densidade e dureza instrumental - tiveram grande influência do PDM, um resíduo heterogêneo. Este estudo demonstra a importância do reaproveitamento de resíduos agroindustriais e a possibilidade de se utilizar a extrusão termoplástica para obtenção de produtos com diferentes propriedades a partir dos parâmetros de otimização.

\section{Palavras-chave: \\ Resíduo Úmido de Cervejaria, cerveja, extrusão termoplástica.}

\section{Introdução}

Anualmente, grandes quantidades de resíduos são geradas pela agroindústria. $\mathrm{Na}$ indústria cervejeira, os principais subprodutos orgânicos são o RUC, constituído por bagaço de malte; a LEV, excesso de levedura; e, em menor quantidade, o PDM, originado do transporte do malte. Estes resíduos possuem alto teor de fibras, proteínas e compostos bioativos. Neste estudo, também se utilizou pó de arroz (PDA), subproduto da indústria de saquê, como fonte de amido.

Entre as técnicas utilizadas na reutilização de subprodutos, a extrusão termoplástica possui muitas vantagens. Este método, que consiste em uma combinação de calor, pressão e cisalhamento, permite a reutilização do subproduto como um todo, além de não gerar novos resíduos. Entretanto, limita-se quanto à umidade e ao tamanho das partículas do material a ser extrusado.

Assim, este projeto teve como objetivos a caracterização dos resíduos e a determinação das melhores proporções dos subprodutos da indústria cervejeira para misturas extrudáveis, a fim de produzir um extrusado com destinação à alimentação animal e de fácil comercialização.

\section{Resultados e Discussão}

Em relação à composição centesimal dos subprodutos, o RUC mostrou ser um resíduo extremamente promissor, já que sua composição indica um material rico em fibras, proteínas e minerais (Tabela 1), embora varie com a formulação da cerveja [1]. Já, a LEV apresentou-se como a principal fonte de proteínas, um macronutriente fundamental na formulação de alimentos destinados a animais. O PDM e O PDA apresentaram uma alta quantidade de carboidratos, caracterizando-se como subprodutos ricos em amido, componente que favorece a expansão dos extrusados, garantindo uma melhor textura ao produto. Devido à alta contagem de coliformes no PDM, o PDA foi escolhido para ser fixado em quantidade mínima na formulação dos blends.

Misturas foram preparadas com 55\% de PDA e os outros $45 \%$ foram compostos de RUC úmido, LEV e PDM. Desse modo, seguindo um delineamento de misturas, foram realizados 9 ensaios. Os produtos extrusados apresentaram cerca de $17 \%$ de proteínas, atividade de água entre 0,38 e 0,67, e umidade entre 6,39\% e $10,37 \%$. Os parâmetros tecnológicos variaram de 1,33 a 1,83 para o IE, 0,45 a $0,71 \mathrm{~g} / \mathrm{cm}^{3}$ para a densidade e 38 a $89 \mathrm{~N}$ para a dureza instrumental. Por meio da análise estatística dos parâmetros dos extrudados, foi realizada a otimização da mistura, visando maximizar o teor proteico e minimizar a umidade dos produtos extrusados finais.

Tabela 1. Caracterização físico-química dos resíduos.

\begin{tabular}{lllll}
\hline & RUC & LEV & PDM & PDA \\
\hline Atividade de água & 1,0117 & 0,9867 & 0,5162 & 0,5303 \\
\hline Umidade (\%) & 78,57 & 85,46 & 7,55 & 9,78 \\
\hline Proteínas (\%, b.s.) & 18,25 & 53,25 & 13,12 & 17,65 \\
\hline Cinzas (\%, b.s.) & 3,81 & 6,79 & 3,69 & 1,26 \\
\hline Lipídeos (\%, b.s.) & 13,58 & 2,52 & 3,36 & 3,38 \\
\hline Fibras totais (\%, b.s.) & 54,52 & 19,88 & 15,03 & 12,22 \\
\hline Carboidratos (\%, b.s.) & 9,84 & 17,55 & 64,79 & 65,49 \\
\hline
\end{tabular}

\section{Conclusões}

A análise da composição centesimal das matérias-primas mostrou o quão ricos nutricionalmente são os subprodutos da indústria cervejeira, demonstrando a importância de estudos para a exploração e reutilização desses resíduos. O estudo dos extrusados mostrou que é possível a reutilização dos subprodutos, sem nenhum pré-tratamento, através da extrusão termoplástica para a formação de um novo produto destinado à alimentação animal.

\section{Agradecimentos}

Gostaria de agradecer à Aline Brito, por todo seu apoio e ensinamentos; à Profa. Caroline por toda a orientação para que este trabalho fosse realizado; e à UNICAMP pelo espaço físico e materiais necessários para a conclusão deste projeto.

${ }^{1}$ HUIGE, N. J. Brewery by-products and effluents. In: PRIEST, FERGUS G. and STEWART, GRAHAM G. Handbook of Brewing. Florida: Taylor \&Francis Group LLC. 2006. p. 655-713. 